\title{
INHIBITION OF GASTRIC DEGRADATION OF OMEPRAZOLE USING A pH-SENSITIVE POLYMER AS A BINDER IN TABLET FORMULATION
}

\author{
EMMANUEL O. OLORUNSOLA ${ }^{1 *}$, IMO E. UDOH ${ }^{2}$, STEPHEN O. MAJEKODUNMI ${ }^{1}$, INIOBONG J. ODIONG ${ }^{1}$, \\ UWAKMFON O. EBONG ${ }^{1}$
}

${ }^{1}$ Department of Pharmaceutics and Pharmaceutical Technology, University of Uyo, Uyo, Nigeria, ${ }^{2}$ Department of Clinical Pharmacy and Biopharmacy, University of Uyo, Uyo, Nigeria

Email: olorunsolaeo@yahoo.com

Received: 06 Feb 2021, Revised and Accepted: 22 Jun 2021

ABSTRACT

Objective: This work was aimed at formulating omeprazole tablets using afzelia gum as a binder that is capable of inhibiting the gastric degradation of the drug.

Methods: Afzelia gum at different concentrations of 0, 5, 10, 15, 20 and $30 \%$ was used as a binder to formulate omeprazole tablets. The tablets were formulated by direct compression and the batches labelled F1 to F6 respectively. A batch containing 15\% hydroxypropyl methylc ellulose (F7) was also formulated. The tablets were characterized; and dissolution in a pH 1.2 dissolution medium over 120 min period was studied. Aliquots taken every 20 min were analyzed by ultraviolet spectrophotometry to determine the amount of drug released and not degraded.

Results: Amounts of drug released and not degraded at time 120 min were $53.1 \%, 57.3 \%, 57.8 \%, 58.8 \%, 62.1 \%, 83.4 \%$ and $90.0 \%$ for F1 to F7 respectively.

Conclusion: Afzelia gum at a concentration of $30 \%$ is suitable for use as a binder in tablet formulation of omeprazole to ensure substantial inhibition of gastric degradation of the drug.

Keywords: Afzelia gum, pH-sensitive, Gastric degradation, Omeprazole

(C) 2021 The Authors. Published by Innovare Academic Sciences Pvt Ltd. This is an open access article under the CC BY license (https://creativecommons.org/licenses/by/4.0/) DOI: https://dx.doi.org/10.22159/ijap.2021v13i5.41980. Journal homepage: https://innovareacademics.in/journals/index.php/ijap

\section{INTRODUCTION}

Omeprazole, a substituted benzimidazole, is a proton pump inhibitor used for the management of active duodenal ulcer, active benign gastric ulcer, gastroesophageal reflux disease (GERD) and erosive oesophagitis [1]. The stability of the drug is a function of $\mathrm{pH}$ as it is rapidly degraded in acidic media, but has acceptable stability under alkaline conditions. The drug is easily degraded by heat or acids [2]

Most formulations of omeprazole are enteric-coated because of the susceptibility to gastric degradation [3, 4]. The absorption of such formulations begins only after they have left the stomach. According to the work of Gul et al. [2], the use of a suitable excipient can also improve the stability of omeprazole in the gastric region and hence increase the bioavailability.

Afzelia africana plant is widely distributed in the tropical region. It is commonly found in West, Central and East Africa. The seed contains about $17 \%$ gum which is xyloglucan hemicellulose. Afzelia gum (AFG) has been characterized in terms of its monosaccharide and oligosaccharide compositions. It contains glucose, xylose and galactose in the ratio 1.3: 1: 0.63 . It also contains small amounts of arabinose, mannose and uronic acid [5].

Xyloglucans, to which afzelia gum belongs, are cell wal polysaccharides that are not soluble in water but can be solubilized by aqueous alkali [6]. Such polymers are capable of protecting drugs from the acidic environment of the stomach [7]. Afzelia gum has been described as a $\mathrm{pH}$-sensitive polymer [8]. It has also been found to be less acidic than hydroxypropyl methylcellulose (HPMC) [8]. The aim of this research work is thus to formulate omeprazole tablets containing this $\mathrm{pH}$-sensitive polymer which has the potential of inhibiting the degradation of the drug in the gastric region.

\section{MATERIALS AND METHODS}

\section{Materials}

Afzelia gum obtained from Afzelia africana seeds as described in the previous work of Olorunsola et al. [5] was used as the $\mathrm{pH}$-sensitive polymer. Other materials used are omeprazole powder (Thode and
Scobel, Hambury, Germany), microcrystalline cellulose (E. Merk Darmstadt, Germany), hydroxypropyl methylcellulose (E. Merk. Darmstadt, Germany), lactose (Riedel De Haenac Seelze, Hannover), magnesium stearate (BDH Poole, England) and talc (BDH Poole, England)

\section{Fourier transform infrared (FTIR) spectroscopy}

Samples of omeprazole powder, afzelia gum and a simple mixture of afzelia gum and omeprazole were separately prepared in $\mathrm{KBr}$ disks in a hydrostatic press at 6-8 tons pressure. FTIR spectra of these prepared samples were recorded at a scanning range of 500 to $5,000 \mathrm{~cm}^{-1}$ using a spectrophotometer (model 8400S, Shimadzu Corporation, Kyoto-Japan).

\section{Formulation of powder blends for compression}

All ingredients were passed through $0.5 \mathrm{~mm}$ sieve mesh and blended for $15 \mathrm{~min}$ before formulation. Mixtures of omeprazole and excipients were prepared as shown in table 1. Calculations were made for a batch size of 100 tablets of weight $250 \mathrm{mg}$ (batch size being $25 \mathrm{~g}$ ). Each batch contained $8 \%$ omeprazole (drug) and $60 \%$ microcrystalline cellulose (direct compression excipient). Batch F1 containing no afzelia gum served as the negative control while batch F7 containing 15\% hydroxypropyl methylcellulose served as the positive control. The test batches F2 to F6 contained 5, 10, 15, 20 and 30\% afzelia gum respectively; and lactose was used as the bulking agent. Prior to the addition of magnesium stearate and talc, the mixtures were mixed thoroughly and then evaluated for some micromeritic properties.

\section{Characterization of powder blends}

Angle of repose $(\theta)$

A funnel was fixed with its tip at a given height $(\mathrm{h}=7.5 \mathrm{~cm})$, above a flat horizontal surface on which a graph paper was placed. Powder was carefully poured through a funnel till the apex of the conical pile just touched the tip of the funnel. The angle of repose was calculated using the formula,

$$
\theta=\tan ^{-1}(\mathrm{~h} / \mathrm{r})
$$

Where $\theta$ is the angle of repose, $h$ is the height of the pile of powder and $r$ is the radius of the base of the cone. 
Table 1: Tablet formula

\begin{tabular}{|c|c|c|c|c|c|c|c|}
\hline \multirow[t]{2}{*}{ Ingredients } & \multicolumn{7}{|c|}{ Batches } \\
\hline & F1 & F2 & F3 & F4 & F5 & F6 & F7 \\
\hline Omeprazole (\%) & 8 & 8 & 8 & 8 & 8 & 8 & 8 \\
\hline Lactose $(\%)$ & 30 & 25 & 20 & 15 & 10 & 0 & 15 \\
\hline Microcrystalline cellulose (\%) & 60 & 60 & 60 & 60 & 60 & 60 & 60 \\
\hline Afzelia gum (\%) & 0 & 5 & 10 & 15 & 20 & 30 & 0 \\
\hline Hydroxypropyl methylcellulose (\%) & 0 & 0 & 0 & 0 & 0 & 0 & 15 \\
\hline Talc $(\%)$ & 1.5 & 1.5 & 1.5 & 1.5 & 1.5 & 1.5 & 1.5 \\
\hline Magnesium stearate (\%) & 0.5 & 0.5 & 0.5 & 0.5 & 0.5 & 0.5 & 0.5 \\
\hline Tablet weight (mg) & 250 & 250 & 250 & 250 & 250 & 250 & 250 \\
\hline
\end{tabular}

\section{True density}

The true density of powder mix was determined using the liquid displacement method. An empty $25 \mathrm{ml}$ pycnometer was weighed (W), filled with xylene and then reweighed $\left(W_{1}\right)$. The difference between $\mathrm{W}_{1}$ and $\mathrm{W}$ was calculated as the weight of xylene $\left(\mathrm{W}_{2}\right)$. One gram sample of the powder mix $\left(\mathrm{W}_{3}\right)$ was transferred into the pycnometer, excess liquid wiped off and the system finally weighed $\left(\mathrm{W}_{4}\right)$ [9]. The true density $D_{t}\left(\mathrm{~g} / \mathrm{cm}^{3}\right)$ of powder mix was calculated as:

$$
D_{t}=\frac{\left(W_{2}\right) \times W_{3}}{25\left(W+W_{2}+W_{3}-W_{4}\right)}
$$

Where $W_{2} / 25$ is equivalent to the density of the non-solvent (xylene)

\section{Compression of powder blends into tablets}

Before compression, the appropriate quantities of magnesium stearate and talc (based on the formula in table 1) were weighed and added to the powder mixture of each batch in a mortar and mixed together to get a homogeneous mixture. The tablets were prepared by direct compression method using a single punch $8.5 \mathrm{~mm}$ diameter) automated tableting machine (Model D63150, Erweka, Germany).

\section{In vitro evaluation of tablets}

\section{Hardness}

For each formulation, the hardness of five tablets was determined using the Monsanto hardness tester (PTB 301, Pharmatest, Switzerland).

\section{Friability}

Friability was determined using a Roche Friability tester which revolves at a speed of $25 \mathrm{rpm}$, dropping the tablets at a distance of 6 inches in each revolution. A sample of pre-weighed tablets (10 tablets for each batch) was placed in the friability tester and allowed to rotate for $4 \mathrm{~min}$. The tablets were de-dusted and then weighed. The procedure was carried out three times for each batch. Friability values were determined as percent weight loss.

\section{Tablet porosity}

The tablet porosity $(\varepsilon)$ was calculated using Equation 3 following determination of the mass $(\mathrm{m})$, radius $(\mathrm{r})$ and thickness $(\mathrm{h})$ of three tablets per batch.

$$
\text { Tablet porosity }=1-\left[\frac{\mathrm{m}}{\mathrm{D}_{\mathrm{t}} \pi \mathrm{r}^{2} \mathrm{~h}}\right] \times 100 \ldots \ldots \ldots \text { (3) }
$$

Where $\mathrm{D}_{\mathrm{t}}$ is the true density of the powder mix and $\frac{\mathrm{m}}{\pi \mathrm{r}^{2} \mathrm{~h}}$ is the density of the tablet.

\section{Disintegration time}

The in vitro disintegration studies were carried out using a tablet disintegration test apparatus (Erweka, Germany). One tablet was placed in each of the six tubes of the basket assembly. The assembly was then suspended in a one-liter beaker containing water maintained at $37 \pm 1^{\circ} \mathrm{C}$. The basket was moved up and down through a distance of 5 to $6 \mathrm{~cm}$ at a frequency of 28 to 32 cycles per minutes.
The time required for complete disintegration of each tablet was recorded.

\section{Dissolution rate}

An in vitro drug release studies of the prepared seven formulations of the tablets was carried out for a period of $120 \mathrm{~min}$ using a sixstation USP basket type apparatus (Unimach RCZ-6C $\mathrm{C}_{3}$, China). A tablet each was placed in each wire mesh basket suspended in 900 $\mathrm{ml} \mathrm{pH} 1.2$ dissolution medium maintained at $37 \pm 1^{\circ} \mathrm{C}$. The basket was rotated at a speed of $50 \mathrm{rpm}$ and the experiment was allowed for $120 \mathrm{~min}$. Samples of $5 \mathrm{ml}$ aliquots were withdrawn from the dissolution medium at 20 min intervals and filtered through a Whatman filter paper No. 2. An equal volume of fresh dissolution medium was replaced to maintain the volume of the medium. The absorbance of each filtered sample was determined at $302 \mathrm{~nm}$ using an ultraviolet spectrophotometer (Labomed Inc., U. S. A.). A graph of cumulative percent drug present in the medium was plotted against time.

\section{Data analysis}

Data were expressed as mean \pm standard deviation. Statistical analysis was done using one-way analysis of variance (ANOVA) followed by Turkey-Kramer multiple comparison tests using GraphPad Instat3 software. $P$ value $<0.05$ was taken as significant.

\section{RESULTS AND DISCUSSION}

\section{Compatibility of omeprazole with afzelia gum}

The FTIR spectra of afzelia gum, omeprazole and afzelia gumomeprazole mixture are shown in fig. 1.

The peak of highest intensity for afzelia gum was noticed at 2,109.7 $\mathrm{cm}^{-1}$. The peak at $1,021.3 \mathrm{~cm}^{-1}$ could be assigned to $\mathrm{O}-\mathrm{H}$ bending vibration. Generally, strong signals in the fingerprint region $(650-$ $1,400 \mathrm{~cm}^{-1}$ ) indicate $\mathrm{C}-\mathrm{H}$ bending of the aromatic ring and $\mathrm{O}-\mathrm{H}$ bending of the hydroxyl group. The absorption peaks at 2,500 to $4,000 \mathrm{~cm}^{-1}$ are indicative of single bonds including $0-\mathrm{H}$ stretching of hydroxyl group and C-H stretching of the aromatic ring [10].

In the spectrum of omeprazole, the strong signals in the fingerprint region (650-1,400 $\left.\mathrm{cm}^{-1}\right)$ indicate $\mathrm{C}-\mathrm{H}$ bending of an aromatic ring. C$\mathrm{O}$ bond of ether and $\mathrm{C}-\mathrm{N}$ bond; the prominent peaks at 987.7 and $1,051.1 \mathrm{~cm}^{-1}$ could be assigned to $\mathrm{C}-\mathrm{C}$ stretching vibrations. The peaks at $1,427.6$ to $1,699.7 \mathrm{~cm}^{-1}$ are typical of the double bond of an aromatic ring. The absorption peaks at 2,500 to $4,000 \mathrm{~cm}^{-1}$ are indicative of single bonds including $\mathrm{C}-\mathrm{H}$ stretching of aromatic ring; the two bands at 3,317.3 and 3,380.7 $\mathrm{cm}^{-1}$ being typical of $\mathrm{N}-\mathrm{H}$ stretching [10]. These functional groups are all present in the omeprazole molecule which is 5-methoxy-2-\{[(4-methoxy-3,5dimethyl pyridine-2-yl)methyl]sulfinyl\}-1H-benzimidazole.

The FTIR spectrum of afzelia gum+omeprazole is very similar to that of omeprazole. The prominent peaks at 987.7 and $1,051.1 \mathrm{~cm}^{-1}$ were retained and could be assigned to $\mathrm{C}-\mathrm{C}$ stretching vibrations. The two bands at 3,324.8 and 3,384.4 $\mathrm{cm}^{-1}$ are typical of $\mathrm{N}-\mathrm{H}$ stretching vibration. All the major peaks observed in FTIR spectrum of pure omeprazole were retained when omeprazole was mixed with afzelia gum. However, there were slight changes in the location of those peaks. 


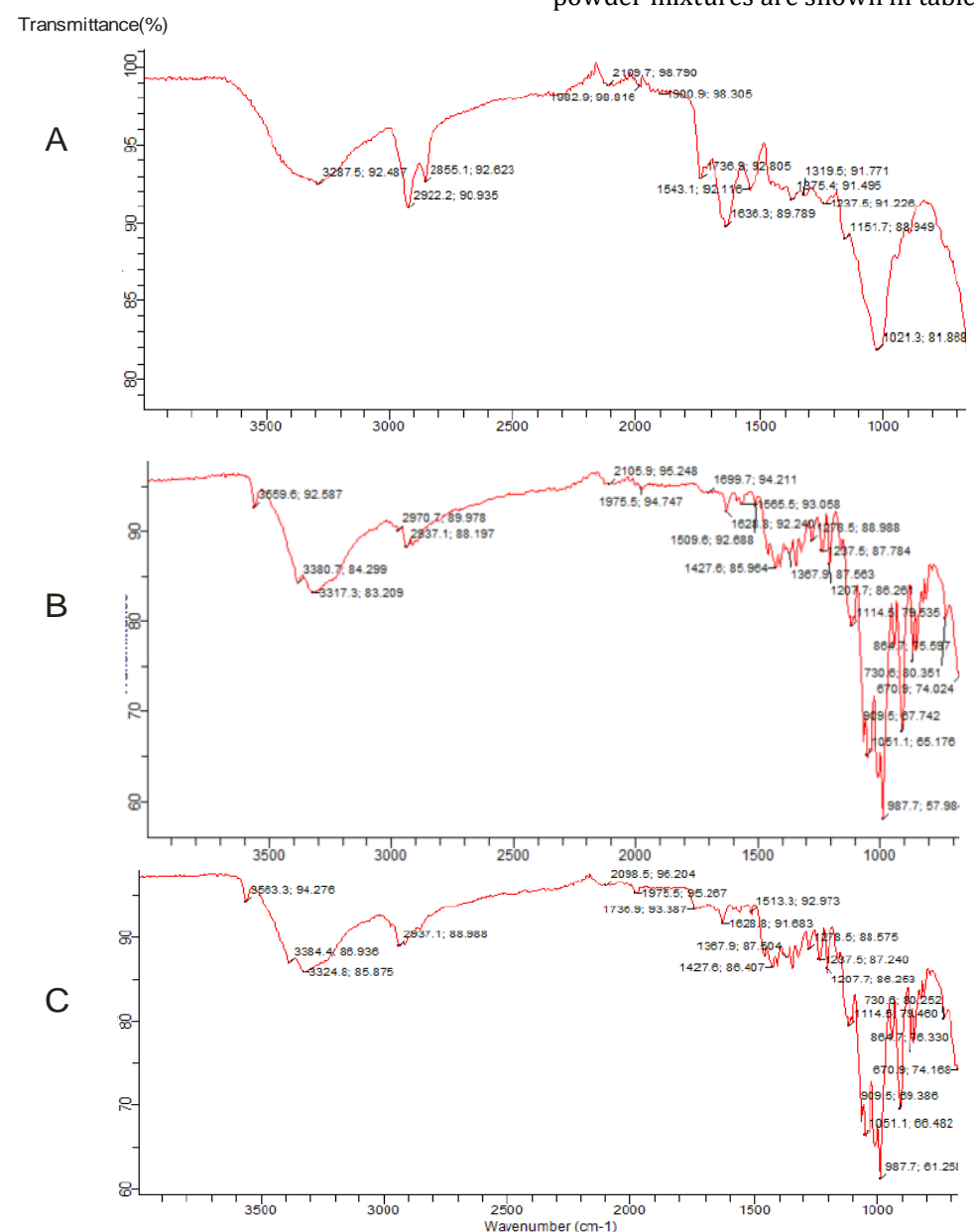

Fig. 1: Fourier transform infrared spectra of (a) afzelia gum (b) omeprazole (c) afzelia gum+omeprazole

Table 2: Micromeritic properties of powder blends

\begin{tabular}{llll}
\hline Batch & Amount of pH-sensitive polymer & Angle of repose $(\circ)$ & True density (g/ml) \\
\hline F1 & 0\% AFG & $38.23 \pm 0.03$ & $1.36 \pm 0.10$ \\
F2 & 5\% AFG & $35.54 \pm 0.05$ & $1.43 \pm 0.04$ \\
F3 & 10\% AFG & $36.44 \pm 0.02$ & $1.45 \pm 0.12$ \\
F4 & 15\% AFG & $37.75 \pm 0.04$ & $1.46 \pm 0.04$ \\
F5 & 20\% AFG & $35.54 \pm 0.02$ & $1.47 \pm 0.02$ \\
F6 & 30\% AFG & $31.33 \pm 0.03$ & $1.47 \pm 0.06$ \\
F7 & $15 \% \mathrm{HPMC}$ & $41.42 \pm 0.06$ & $1.43 \pm 0.02$ \\
\hline
\end{tabular}

Values shown are mean \pm SD $(n=3)$

According to Al-Hashemi and Al-Amoudi [11], powders can be described as very free-flowing, free-flowing, passable (or fairly flowing), cohesive or very cohesive based on angles of repose $<30^{\circ}$, $30-38^{\circ}, 38-45^{\circ}, 45-55^{\circ}$ and $>55^{\circ}$ respectively. Hence, batches $\mathrm{F} 2$ to F6 containing varying percentages of afzelia gum (5-30\%) can be described as free-flowing while F1 without afzelia gum and F7 containing $15 \%$ hydroxypropyl methylcellulose can be described as passable requiring flow aids for acceptable flow. Talc was added to all the batches to ensure good powder flow while magnesium stearate was added to reduce friction during compression and tablet ejection.

The result of the true density shows that batch F1 which contains no afzelia gum has the lowest value implying that the presence of the highest amount of lactose in that batch was responsible for the lowest value. However, the values of the true density are not significantly different $(1.36-1.47 \mathrm{~g} / \mathrm{ml})$ because all the batches contain $60 \%$ microcrystalline cellulose which was incorporated as the direct compression excipient to all the batches. This is about the value $(1.56 \mathrm{~g} / \mathrm{ml})$ reported by Reus-Medina et al. [12] for Avicel PH102. The true densities of the various powder mixtures used for tablet preparation were determined as they are required for calculating tablet porosity.

\section{Tablet properties}

The mechanical and release properties of the tablets are shown in table 3.

Crushing strength is a measure of the compression force which when applied diametrically to the tablet causes a fracture. The crushing strength values of the tablets were generally low. This cannot be isolated from the fact that direct compression generally 
produces weaker tablets compared to wet granulation [13]. Only batches F1, F2 and F7 containing 0\% AFG, 5\% AFG and 15\% HPMC had crushing strength above $4 \mathrm{kgF}$ which is required to pass the test for crushing strength [14].

Table 3: Mechanical and release properties of tablets

\begin{tabular}{|c|c|c|c|c|c|}
\hline Batch & Amount of pH-sensitive polymer & Crushing strength (kgF) & Friability & Porosity (\%) & Disintegration time (min) \\
\hline F1 & $0 \% \mathrm{AFG}$ & $5.5 \pm 0.03$ & $0.31 \pm 0.02$ & $9.3 \pm 0.04$ & $10.12 \pm 0.02$ \\
\hline F2 & $5 \%$ AFG & $4.0 \pm 0.02$ & $0.79 \pm 0.04$ & $16.3 \pm 0.01$ & $3.26 \pm 0.01$ \\
\hline F3 & $10 \% \mathrm{AFG}$ & $3.5 \pm 0.01$ & $1.06 \pm 0.02$ & $21.0 \pm 0.02$ & $2.25 \pm 0.01$ \\
\hline $\mathrm{F} 4$ & $15 \% \mathrm{AFG}$ & $3.0 \pm 0.02$ & $1.10 \pm 0.01$ & $20.5 \pm 0.02$ & $2.09 \pm 0.06$ \\
\hline F5 & $20 \% \mathrm{AFG}$ & $2.8 \pm 0.01$ & $1.50 \pm 0.03$ & $22.1 \pm 0.01$ & $2.09 \pm 0.05$ \\
\hline F6 & $30 \% \mathrm{AFG}$ & $2.5 \pm 0.04$ & $1.60 \pm 0.03$ & $23.9 \pm 0.01$ & $1.53 \pm 0.04$ \\
\hline F7 & 15\% HPMC & $5.0 \pm 0.03$ & $1.71 \pm 0.06$ & $19.8 \pm 0.05$ & $5.08 \pm 0.04$ \\
\hline
\end{tabular}

Values shown are mean \pm SD

The friability value was less than $1 \%$ for F1 and F2 while F3-F7 had values greater than $1 \%$, an indication that F1 and F2 tablets are more mechanically stable than F3-F7. A friability value less than $1 \%$ is required for a tablet to pass the friability test. The mechanical strength of tablets produced upon compression is the most essential requirement of directly compressed excipients. Hence, it can be concluded that incorporation of afzelia gum up to $10 \%$ in direct compression of omeprazole tablet leads to the production of weak tablets.

The porosity of the tablets increased with an increase in the concentration of afzelia gum. Tablet properties such as mechanical strength and disintegration time are known to be influenced by pore structure. A tablet of low porosity is likely to have high mechanical strength and a long disintegration time. The decrease in crushing strength and increase in friability of the tablets observed with an increase in the concentration of the $\mathrm{pH}$-sensitive polymer (afzelia gum) can be explained by the observed increase in porosity [15].

Disintegration time is a measure of the tendency of a tablet to break (disintegration) into small particles to release the drug. It is a useful means of accessing the potential significance of formulation and process variables in the biopharmaceutical properties of the tablets and as a control procedure to evaluate the quality and reproducibility of the tablet production. From the result, all the batches had disintegration time less than $15 \mathrm{~min}$.

\section{Drug release and stability}

The dissolution profile of omeprazole combined with its stability is shown in fig. 2. Since omeprazole is degraded under an acidic condition [2], the amount of omeprazole detected by the ultraviolet spectrophotometry at the wavelength of maximum absorption is equivalent to the amount of drug released and not degraded. The test determined the amount of the drug released and available at various time intervals.

Batch F1 containing $0 \%$ AFG was found to be the fastest to dissolve, with $95.7 \%$ drug released and available within $20 \mathrm{~min}$ but only $53.1 \%$ was remaining at time $120 \mathrm{~min}$. Batches $\mathrm{F} 2$ and F3 also had their maximum drug release within 20 min with $90.5 \%$ and $70.6 \%$ drug present respectively. However, less than $60 \%$ of the drug was remaining at time $120 \mathrm{~min}$ for each of the two batches. There was a gradual drug release from batches F5 and F6 and also gradual drug degradation such that 62.1 and $83.4 \%$ were available respectively at time $120 \mathrm{~min}$.

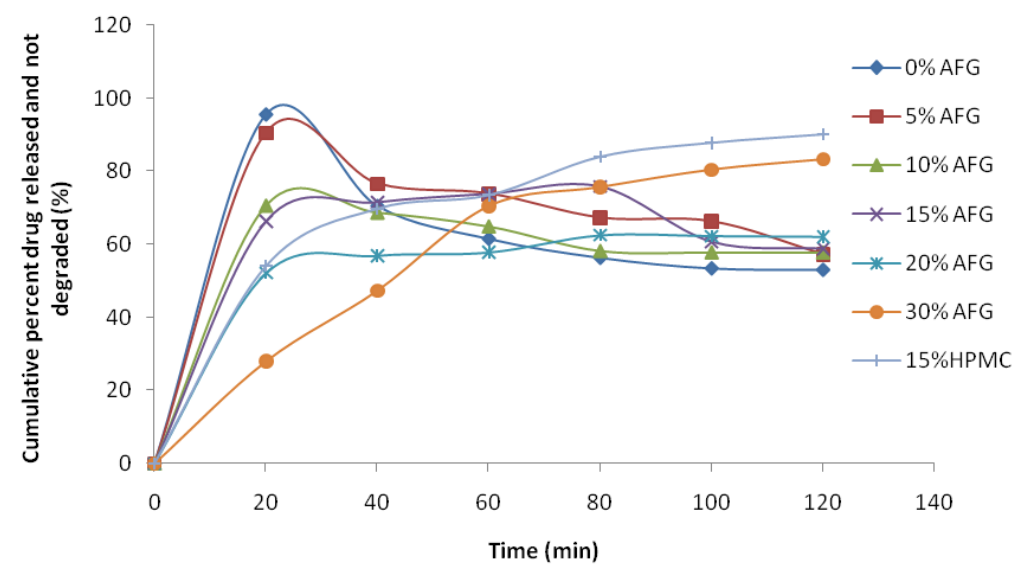

Fig. 2: Graph of cumulative percent drug released and not degraded versus time

Afzelia gum is poorly water-soluble but can be solubilized by aqueous alkali [6]. It is also less acidic than hydroxypropyl methylcellulose [8]. Hence, even though the disintegration times of the tablets were short, afzelia gum caused a slow-release and inhibited the degradation of omeprazole under $\mathrm{pH} 1.2$ condition. This behaviour is in agreement with the work of Sun et al. [7] where a $\mathrm{pH}$-sensitive hydrogel caused a slow drug release. The ability of afzelia gum to exhibit this behavior increased with an increase in its concentration in the tablet.

The normal gastric residence time is $5 \mathrm{~min}$ to $2 \mathrm{~h}$ depending on whether the stomach is in the fed or fasted state [16]; hence, $30 \%$ afzelia gum incorporated in direct compression of omeprazole is suitable to preserve the drug from gastric degradation to the extent of $83.4 \%$. This will allow the circumvention of the more laborious process of enteric coating. However, the gum at that concentration yielded tablets with low crushing strength.

\section{CONCLUSION}

Afzelia gum at a concentration of $30 \%$ is suitable for use as a binder in tablet formulation of omeprazole to ensure substantial inhibition of gastric degradation of the drug.

\section{FUNDING}




\section{AUTHORS CONTRIBUTIONS}

Emmanuel O. Olorunsola was involved in the design of the work statistical analysis and drafting of the manuscript; Imo E. Udoh and Stephen O. Majekodunmi were involved in the technical support of the work and critical revision of the manuscript while Iniobong J. Odiong and Uwakmfon 0. Ebong were involved in data acquisition and analysis.

\section{CONFLICT OF INTERESTS}

There is no conflict of interest of any form in respect of this paper.

\section{REFERENCES}

1. Kallen BAJ. Use of omeprazole during pregnancy-no hazard demonstrated in 955 infants exposed during pregnancy. Eur J Obst Gyn Reprod Biol 1999;96:63-8.

2. Gul W, Sajid S, Hamid F, Bhatti S. Effect of acidic $\mathrm{pH}$ and heat on the degradation of omeprazole and esomeprazole. Pharma Innov J 2015;4:19-21.

3. DiGiacinto JL, Olsen KM, Bergman KL, Hoie EB. Stability of suspension formulations of lansoprazole and omeprazole stored in amber-colored plastic oral syringes. Annals Pharmacother 2000;34:600-5.

4. El-Sayed E, Boraie NA, Ismail FA, El-Khardagui LK, Khalil SA. Assessment of the pharmaceutical quality of omeprazole capsule brands marketed in Egypt. Eastern J 2007;13:1427-37.

5. Olorunsola EO, Bhatia PG, Tytler BA, Adikwu MU. Some chemical characteristics of novel hemicellulosic gums from seeds of Afzelia africana and Prosopis africana. West Afr J Pharm 2014;25:31-40.

6. Park YB, Cosgrove DJ. Xyloglucan and its interactions with other components of the growing cell wall. Plant Cell Physiol 2015;56:180-94.
7. Sun XF, Wang HH, Jing ZX, Mohanathas R. Hemicellulose-based $\mathrm{pH}$-sensitive and biodegradable hydrogel for controlled drug delivery. Carbohydrate Polym 2013;92:1357-66.

8. Builders PF, Chukwu C, Obidike I, Builders MI, Attama AA, Adikwu MU. A novel xyloglucan gum from seeds of Afzelia africana Se. Pers.: some functional and physicochemical properties. Int J Green Pharm 2009;3:112-8.

9. Olorunsola EO, Isah AB, Allagh TS. Compression and mechanical properties of microcrystalline sweet potato starch. Nig J Pharm Sci 2014;13:5-11.

10. Coutts RT. Infrared spectroscopy. In: Chatten LG. editor. Pharmaceutical chemistry-instrumental techniques. New Delhi India: CBS Publishers and Distributors PVT Ltd; 2008. p. 59125.

11. Hashemi HMB, Al-Amoudi SBO. A review on the angle of repose of granular materials. Powd Technol 2018;330:397-417.

12. Reus Medina M, Lanz M, Kumar V, Leuenberger H. Comparative evaluation of the powder properties and compression behaviour of a new cellulose-based direct compression excipient and Avicel PH-102. J Pharm Pharmacol 2004;56:9516.

13. Bose V, Sree R. Design and development of gastroretentive drug delivery system of ciprofloxacin hydrochloride. Asian J Pharm Clin Res 2018;11:141-6.

14. Nascimento NCDO, Boldo EM. Evaluation of mechanical strength after compression of metformin $500 \mathrm{mg}$ tablets formed by different wet routes. Int J Pharm Pharm Sci 2021;13:30-4.

15. Juppo AM. Relationship between breaking force and pore structure of lactose, glucose and mannitol tablets. Int J Pharm 1996;127:95-102.

16. Ashford M. Gastrointestinal tract-physiology and absorption. In: Aulton ME. editor. Aulton's Pharmaceutics: The design and manufacture of medicine. $3^{\text {rd }}$ edition. Hungary: Churchill Livingstone Elsevier; 2007. p. 270-85. 